\title{
Influence of Ferronickel Slag on Impermeability of Seawater-Corroded Cement Soil Using an Electrochemical Test
}

\author{
Sanshan Chen $\left(\mathbb{D},{ }^{1}\right.$ Feng Chen $\mathbb{D},{ }^{1,2}$ and Shenghao Tong $\mathbb{D}^{3}$ \\ ${ }^{1}$ College of Engineering, Fujian Jiangxia University, Fuzhou 350108, China \\ ${ }^{2}$ College of Environment and Resources, Fuzhou University, Fuzhou 350108, China \\ ${ }^{3}$ CSCEC Strait (Xiamen) Construction and Development Co., Ltd., Xiamen 361021, China \\ Correspondence should be addressed to Feng Chen; 780002747@qq.com
}

Received 11 August 2021; Revised 4 December 2021; Accepted 29 December 2021; Published 2 February 2022

Academic Editor: Zhen-Jun Wang

Copyright ( $\odot 2022$ Sanshan Chen et al. This is an open access article distributed under the Creative Commons Attribution License, which permits unrestricted use, distribution, and reproduction in any medium, provided the original work is properly cited.

Since the traditional penetration testing of cement soil is time-consuming, this paper introduces a new electrochemical testing method to study the effect of ferronickel slag powder on improving the impermeability of cement soil in the corrosive seawater environment. To this end, the mercury intrusion test was employed to analyze the change in the pore characteristics of cement soil, and the variation in the impermeability of cement soil was further explained from a microscopic point of view. The test results show that using the electrochemical method to test the impermeability of cement soil dramatically improves the efficiency of testing. The impermeability of cement soil gradually rises with an increase in its ferronickel slag powder content. Moreover, the optimal mass replacement ratio of the ferronickel slag powder and mineral powder composite to cement is $40 \%$ in the testing range of $0-40 \%$. The mercury intrusion test results also confirm that the addition of ferronickel slag powder can decrease the most probable pore size and total porosity of cement soil; further, from a microscopic perspective, the ferronickel slag powder can help reduce the corrosion of cement soil by seawater. The above test conclusions are consistent with the results of the traditional permeability test. Our findings not only imply that ferronickel slag powder can lessen the effect of seawater on the corrosion of cement soil but prove that the electrochemical test is a reliable and straightforward method for determining the impermeability of cement soil.

\section{Introduction}

Cement soil is widely used in the offshore engineering of coastal cities due to the advantages of its suitable materials, easy construction, and low price. Seawater is a complex solution, and soluble salt ions can corrode the cement soil in seawater such as $\mathrm{Cl}^{-}, \mathrm{SO}_{4}^{2-}$, and $\mathrm{Mg}^{2+}$ [1]. Extensive research indicates that corrosive ions change the composition and structure of cement soil, reduce its strength, and increase its permeability, affecting the service life of related projects [2-7]. There are plenty of studies on the reduction in the strength of cement soil caused by seawater corrosion. Therefore, this paper focuses on how to improve and quickly evaluate the impermeability of cement soil.

Most scholars have proposed adding admixtures to cement soil to improve its impermeability. For example, some scholars added basalt fiber $[8,9]$, bentonite [10], coalbearing metakaolin [11], graphene oxide [12], waste glass fiber [13], and air foam [14] into cement soil, and it was reported that these admixtures have a positive effect on improving the impermeability of cement soil. In this context, this paper investigates adding ferronickel slag powder to cement soil.

Ferronickel slag powder is a kind of industrial waste slag discharged from smelting metal, and its main components are $\mathrm{SiO}_{2}, \mathrm{Fe}_{2} \mathrm{O}_{3}$, and $\mathrm{Al}_{2} \mathrm{O}_{3}$ [15]. Moreover, ferronickel slag powder obtained by water quenching contains many amorphous vitreous bodies with potential activity [16, 17]. Some scholars have evaluated the safety of ferronickel slag powder, indicating that its corrosivity, leaching toxicity, and radioactivity are not harmful. Using it as a substitute for cement has significant environmental benefits in waste 
utilization practice $[18,19]$. In addition, in our previous study, we found that the addition of appropriate ferronickel slag powder could improve the strength of cement soil [20], which lays a theoretical foundation for exploring the influence of ferronickel slag powder on the impermeability of cement soil.

It is necessary to examine whether adding ferronickel slag powder can enhance the impermeability of cement soil. At present, the impermeability of cement soil is chiefly evaluated by using the permeability coefficient. However, the permeability coefficient of cement soil is small, usually in the order of $10^{-8}-10^{-9} \mathrm{~cm} / \mathrm{s}$, so the evaluation takes a long time using conventional testing methods [21]. Therefore, this work employs an electrochemical testing method to reduce the cost and shorten the test time. This method uses the electrochemical acceleration of the corrosion of steel bars to reflect the corrosion degree of cement soil, which can be used to determine the ability of soil to resist the invasion of corrosive substances and shows the impermeability of cement soil.

By considering the continuous construction of offshore engineering structures worldwide and recycling of industrial waste residues such as ferronickel slag powder, this paper added various amounts of ferronickel slag powder to cement soil and used an electrochemical test to quickly evaluate the influence of ferronickel slag powder on the impermeability of seawater-corroded cement soil. Finally, based on the mercury intrusion test, the change law of the impermeability of cement soil containing ferronickel slag powder was analyzed in the corrosive seawater environment from the perspective of the variation in the pore size.

\section{Experimental Analysis of Permeability Tests}

\subsection{Electrochemical Test}

2.1.1. Electrochemical Testing Principles. The main components of construction steel are iron and carbon. Under normal circumstances, steel bars embedded in the cement soil are not easily corroded because they are in an alkaline medium. However, with the invasion of seawater solution, water molecules enter the pores of cement soil, as shown in Figure 1. The steel bars undergo oxygen absorption and corrosion with the participation of water molecules, and then red rust is formed on their surface. The electrode reaction formulas for the corrosion of steel are as follows:

$$
\begin{gathered}
\mathrm{Fe} \longrightarrow \mathrm{Fe}^{2+}+2 \mathrm{e}^{-} \\
\frac{1}{2} \mathrm{O}_{2}+\mathrm{H}_{2} \mathrm{O}+2 \mathrm{e} \longrightarrow 2 \mathrm{OH}^{-}
\end{gathered}
$$

where Equation (1) refers to the anode and Equation (2) addresses the cathode.

After the second-order anode reaction, rust is formed on the surface of steel:

$$
\begin{aligned}
\mathrm{Fe}^{2+}+2 \mathrm{OH}^{-} & \longrightarrow \mathrm{Fe}(\mathrm{OH})_{2} \\
2 \mathrm{Fe}(\mathrm{OH})_{2}+\frac{1}{2} \mathrm{O}_{2}+\mathrm{H}_{2} \mathrm{O} & \longrightarrow 2 \mathrm{Fe}(\mathrm{OH})_{3}
\end{aligned}
$$

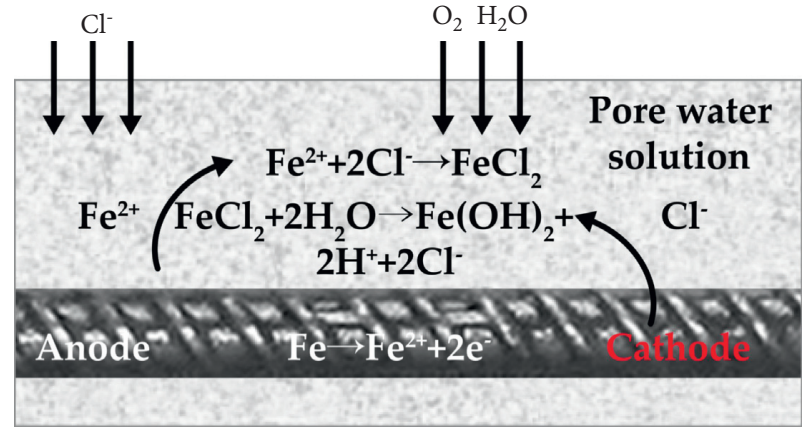

Figure 1: The corrosion mechanism of steel bars [22].

In the corrosive seawater environment, $\mathrm{Cl}^{-}$ions form the most influential corrosive medium. $\mathrm{Cl}^{-}$ions compete with $\mathrm{OH}^{-}$ions for the $\mathrm{Fe}^{2+}$ from the corrosion in the seawater environment. As shown in Figure 1, when the chloride ions in the electrolyte migrate to the anode and reach a particular concentration on the surface of the steel bar, they produce green rust $\mathrm{FeCl}_{2} \cdot 4 \mathrm{H}_{2} \mathrm{O}$, as expressed in Equation (4). When $\mathrm{FeCl}_{2} \cdot 4 \mathrm{H}_{2} \mathrm{O}$ migrates from the anode to the pores of cement soil containing ferronickel slag powder with a higher oxygen content, it decomposes into brown iron rust $\mathrm{Fe}(\mathrm{OH})_{2}$, as given in Equation (5). The brown iron rust is deposited near the anode of the cement soil electrolytic cell system and simultaneously releases hydrogen ions and chloride ions back to the anode; hence, the pore fluid near the anode area is acidified, and chloride ions bring more iron ions. Therefore, although chloride ions do not constitute corrosion products and are not consumed during the corrosion process, they can accelerate the corrosion of steel bars [23]. In the electrochemical test, the corrosion process is accelerated by electrification; therefore, the impermeability performance of cement soil samples with different proportions can be evaluated more quickly.

$$
\begin{gathered}
\mathrm{Fe}^{2+}+2 \mathrm{Cl}^{-}+4 \mathrm{H}_{2} \mathrm{O} \longrightarrow \mathrm{FeCl}_{2} \cdot 4 \mathrm{H}_{2} \mathrm{O} \\
\mathrm{FeCl}_{2} \cdot 4 \mathrm{H}_{2} \mathrm{O} \longrightarrow \mathrm{Fe}(\mathrm{OH})_{2} \downarrow+2 \mathrm{H}^{2+}+2 \mathrm{Cl}^{-}+2 \mathrm{H}_{2} \mathrm{O}
\end{gathered}
$$

2.1.2. Materials. The raw materials for preparing the cement soil samples were silt, ordinary Portland cement, mineral powder, ferronickel slag powder, and water. To compare our data with the traditional penetration test results, the properties and parameters of the raw materials selected in this work were consistent with those employed [24]. Pure tap water after purification was used for the preparation of specimens. The $\mathrm{pH}$ value of the silt soil was 6.82 , and Table 1 lists its basic physical and mechanical indices. The chosen cement was qualified ordinary Portland cement (P.O. 42.5), and Table 2 tabulates its chemical composition.

The ferronickel slag powder and the mineral powder were purchased from Fujian Yuanxin Environmental Protection Technology Co., Ltd., China. The average particle size of the ferronickel slag powder and the mineral powder ranged from 0.27 to $4.38 \mu \mathrm{m}$ and from 0.65 to $5.23 \mu \mathrm{m}$, respectively. After investigation and practice, the company 
TABLe 1: The fundamental physical and mechanical indices of the silt soil.

\begin{tabular}{|c|c|c|c|c|c|c|c|}
\hline $\begin{array}{l}\text { Soil } \\
\text { sample }\end{array}$ & $\begin{array}{c}\text { Moisture content, } \\
w(\%)\end{array}$ & $\begin{array}{c}\text { Unit weight, } r \\
\left(\mathrm{kN} / \mathrm{m}^{3}\right)\end{array}$ & $\begin{array}{l}\text { Porosity, } n \\
(\%)\end{array}$ & $\begin{array}{c}\text { Liquid limit, } \\
W_{L}(\%)\end{array}$ & $\begin{array}{c}\text { Plastic limit, } \\
W_{p}(\%)\end{array}$ & $\begin{array}{c}\text { Plasticity index, } \\
I_{p}(-)\end{array}$ & $\begin{array}{c}\text { Liquidity index, } \\
I_{L}(-)\end{array}$ \\
\hline Silt & 58.5 & 16.01 & 60.52 & 49 & 29.3 & 19.8 & 1.47 \\
\hline
\end{tabular}

Table 2: The chemical composition of cement.

\begin{tabular}{lccccccccc}
\hline Chemical composition & $\mathrm{SO}_{3}$ & $\mathrm{MgO}$ & $\mathrm{CaO}$ & $\mathrm{SiO}_{2}$ & $\mathrm{Al}_{2} \mathrm{O}_{3}$ & $\mathrm{Fe}_{2} \mathrm{O}_{3}$ & $\mathrm{f}-\mathrm{CaO}$ & Others & Loss of ignition \\
\hline Mass percent (\%) & 2.89 & 2.05 & 62.55 & 21.69 & 4.38 & 3.34 & 0.57 & 0.84 & 1.59 \\
\hline
\end{tabular}

found that adding an appropriate amount of mineral powder was beneficial for stimulating the activity of ferronickel slag powder. Therefore, blast furnace ferronickel slag powder and granulated blast furnace mineral powder were mixed at a mass ratio of $2: 1$. The current market price of ordinary Portland cement is about twice that of the ferronickel slag powder composite, highlighting that this composite enjoys the advantage of low price. Table 3 presents the chemical composition of the ferronickel slag powder and the mineral powder. When there is no specific explanation in the subsequent result analysis, the ferronickel slag powder refers to the composite of the ferronickel slag powder and the mineral powder.

Moreover, the corrosive seawater environment was simulated by an artificial laboratory solution, the formula and main salt content of which are tabulated in Table 4.

2.1.3. Testing Scheme. The influencing factors in the experiments were the content of the ferronickel slag powder and mineral powder composite, the curing condition, and the curing period. Table 5 presents the electrochemical testing scheme of the cement soil.

The content of the ferronickel slag powder and mineral powder composite: in the sample preparing process, the total mass mixing ratio of the cementitious materials (cement, ferronickel slag powder, and mineral powder) was $15 \%$. In order to explore the influence of the ferronickel slag powder and the mineral powder on the impermeability of the cement soil, we set the mass replacement ratio of the ferronickel slag powder and mineral powder composite to cement (defined as the composite mass/cement mass $\times 100 \%$ ) at $0 \%, 10 \%$, $20 \%, 30 \%$, and $40 \%$.

There are two types of curing environments: the purified water curing environment and the seawater curing environment.

According to the recommended value of the curing period of cement soil given in the specification described elsewhere [25], the curing period of the cement samples was considered 28 days and 90 days. Six samples were made for each mixing ratio to avoid errors in the test results; three samples were used for 28-day curing analysis and the others for 90 -day curing analysis.

2.1.4. Testing Method. According to the testing principle, the cement soil testing block with steel bars should be constructed based on the proportions of all the raw materials, including silt, ordinary Portland cement, mineral powder, ferronickel slag powder, and water, given in the testing scheme, as shown in Figure 2. After curing and mold removal, the samples with different design ratios were immersed in the solution of purified water and seawater for the design curing periods of 28 and 90 days.

After immersion in the solution, the corrosion of the steel bars in the cement soil sample was accelerated by electrification using a comprehensive electrochemical tester. After the corrosion was complete, the "self-corrosion potential" and "actual corrosion rate" of the steel bars were measured using the testing equipment and the "weighing method," respectively. Finally, the influence of three different factors on the impermeability of the cement soil was evaluated by these two indices.

\subsubsection{Testing Procedure.}

(1) Before preparing the samples, a plain round bar with a diameter of $10 \mathrm{~mm}$ and a length of $90 \mathrm{~mm}$ was brushed off rust, polished, rinsed, and dried in an oven for $4 \mathrm{~h}$. The initial weight and initial length of the steel bar also measured $m$ and $\sigma$, respectively. As shown in Figures 3 and 4, the steel bars were wrapped in a gauze impregnated with epoxy resin to prevent water or seawater from entering the gap between the steel bar and the cement soil.

(2) The cement slurry was prepared according to the design mix ratio of the testing scheme. After preparation, the cement slurry was poured into the wet soil and mixed evenly using a mortar mixer. According to the specification described in ref [25], the standard dimensions of the mortar cubes were $70.7 \mathrm{~mm} \times 70.7 \mathrm{~mm} \times 70.7 \mathrm{~mm}$. When the mortar samples were tapped and formed, the steel bar after the anticorrosion treatment was inserted vertically in the middle of the sample, and the position of the steel bar was fixed by using a thin iron wire. Figure 5 depicts the actual cement soil sample. Afterward, the samples were placed in a standard curing room at room temperature $\left(20 \pm 3^{\circ} \mathrm{C}\right)$ for $48 \mathrm{~h}$, and the test molds were then removed. Finally, the demolded cement soil samples were immersed and cured in a purified water curing box and a seawater curing box for the design curing period. Figure 6 illustrates the sample cured using the seawater curing box. 
TABLE 3: The chemical composition of the ferronickel slag powder and mineral powder.

\begin{tabular}{lccccccccc}
\hline Ingredient & $\mathrm{SiO}_{2}$ & $\mathrm{Al}_{2} \mathrm{O}_{3}$ & $\mathrm{CaO}$ & $\mathrm{MgO}$ & $\mathrm{TiO}_{2}$ & $\mathrm{MnO}$ & $\mathrm{Fe}_{2} \mathrm{O}_{3}$ & $\mathrm{SO}_{3}$ & Loss of ignition \\
\hline Ferronickel slag powder (\%) & 35.82 & 21.46 & 29.22 & 9.46 & 0.78 & 0.57 & 1.33 & 0.16 & 2.43 \\
Mineral powder (\%) & 32.00 & 16.81 & 36.12 & 10.59 & 0.93 & 0.9 & 2.29 & 0.14 & 0.16 \\
\hline
\end{tabular}

TABLE 4: The main salt content of the artificial seawater.

\begin{tabular}{lcccccccc}
\hline Salt & $\mathrm{NaCl}$ & $\mathrm{MgCl}_{2}$ & $\mathrm{MgSO}_{4}$ & $\mathrm{CaSO}_{4}$ & $\mathrm{~K}_{2} \mathrm{SO}_{4}$ & $\mathrm{CaCO}_{3}$ & $\mathrm{MgBr}_{2}$ & $\mathrm{Total}$ \\
\hline Content (\%) & 27.21 & 3.81 & 1.66 & 1.26 & 0.86 & 0.12 & 0.08 & 35 \\
\hline
\end{tabular}

TABLE 5: The electrochemical testing plan.

\begin{tabular}{|c|c|c|c|c|c|c|c|}
\hline No. & $\begin{array}{c}\text { Total mass mixing } \\
\text { ratio of } \\
\text { cementitious } \\
\text { materials (\%) }\end{array}$ & $\begin{array}{c}\text { Water-to-cement } \\
\text { ratio }(-)\end{array}$ & $\begin{array}{l}\text { Mass replacement } \\
\text { ratio of the ferronickel slag } \\
\text { powder and mineral powder } \\
\text { composite to cement }(\%)\end{array}$ & $\begin{array}{l}\text { Actual mixing ratio of the } \\
\text { ferronickel slag powder } \\
\text { and mineral powder } \\
\text { composite }(\%)\end{array}$ & $\begin{array}{c}\text { Curing } \\
\text { condition (-) }\end{array}$ & \multicolumn{2}{|c|}{$\begin{array}{c}\text { Curing } \\
\text { period } \\
\text { (day) }\end{array}$} \\
\hline A-0 & 15 & 0.5 & 0 & 0 & Purified water & 28 & 90 \\
\hline A-1 & 15 & 0.5 & 10 & 1.5 & Purified water & 28 & 90 \\
\hline A-2 & 15 & 0.5 & 20 & 3 & Purified water & 28 & 90 \\
\hline A-3 & 15 & 0.5 & 30 & 4.5 & Purified water & 28 & 90 \\
\hline A-4 & 15 & 0.5 & 40 & 6 & Purified water & 28 & 90 \\
\hline B-0 & 15 & 0.5 & 0 & 0 & Seawater & 28 & 90 \\
\hline B-1 & 15 & 0.5 & 10 & 1.5 & Seawater & 28 & 90 \\
\hline B-2 & 15 & 0.5 & 20 & 3 & Seawater & 28 & 90 \\
\hline B-3 & 15 & 0.5 & 30 & 4.5 & Seawater & 28 & 90 \\
\hline B-4 & 15 & 0.5 & 40 & 6 & Seawater & 28 & 90 \\
\hline
\end{tabular}

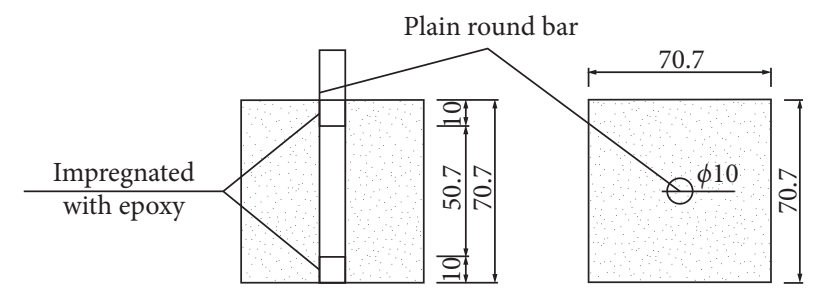

Figure 2: A schematic diagram of the electrochemical sample.

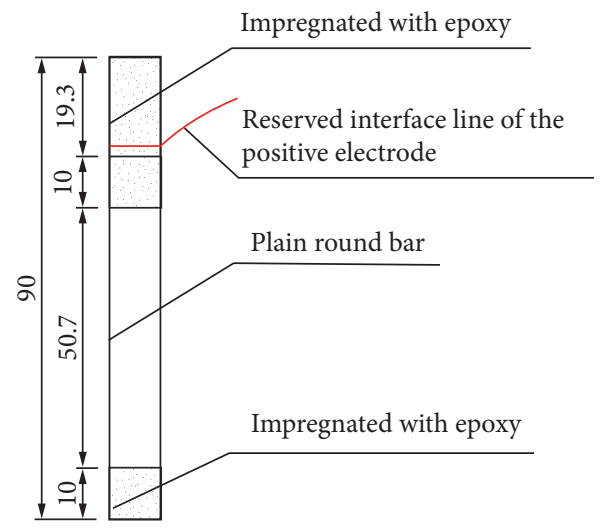

Figure 3: A schematic of the anticorrosion treatment of the steel bar. 


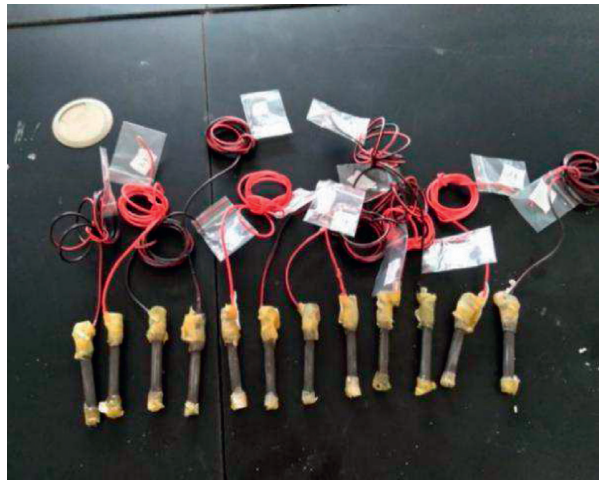

FIGURE 4: Steel bars after the anticorrosion treatment.

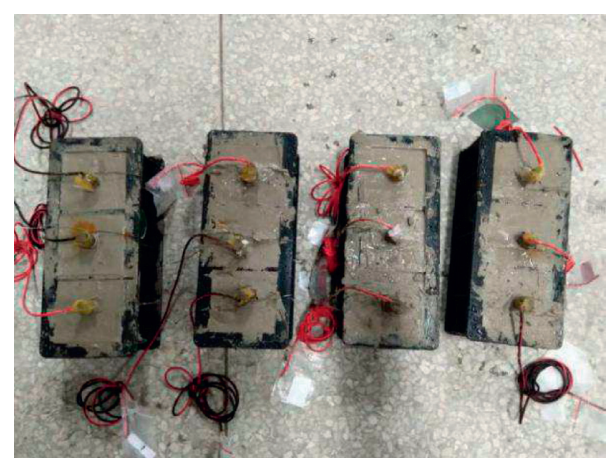

Figure 5: The actual cement soil samples.

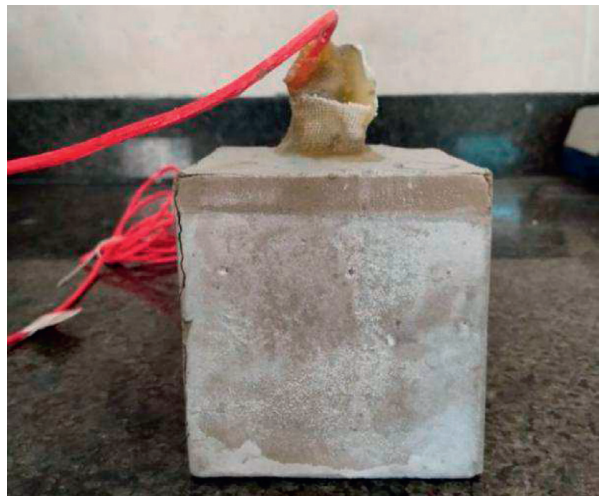

Figure 6: The cement soil sample cured using the seawater curing box.

(3) After the sample was cured for the design curing period, the sample was placed in $35 \%$ o $\mathrm{NaCl}$ solution for 3 days. Then, it was put into a plastic bucket containing $35 \%$ o $\mathrm{NaCl}$ electrolytic solution to be corroded for $24 \mathrm{~h}$ at a constant voltage of $2 \mathrm{~V}$. The positive electrode of the power supply with a constant voltage and a constant current was connected to the reserved wire of the steel bar, and the negative electrode was connected to the stainless steel plate. After completing this stage, the power was disconnected, and the sample was placed in the $\mathrm{NaCl}$ electrolyte solution for another 3 days.
(4) PARSTAT 4000 (Princeton Applied Research, the USA) electrochemical comprehensive tester was employed to test the corrosion degree of the steel bars. The test was conducted using a three-electrode testing method, in which the steel bar embedded in the cement soil was the working electrode, the saturated calomel electrode was the reference electrode, and the stainless steel plate was the auxiliary electrode, as displayed in Figure 7.

(5) Power was switched on to accelerate the corrosion of the steel bars, as depicted in Figure 8. Afterward, the cement soil sample was broken, and the steel bar was 


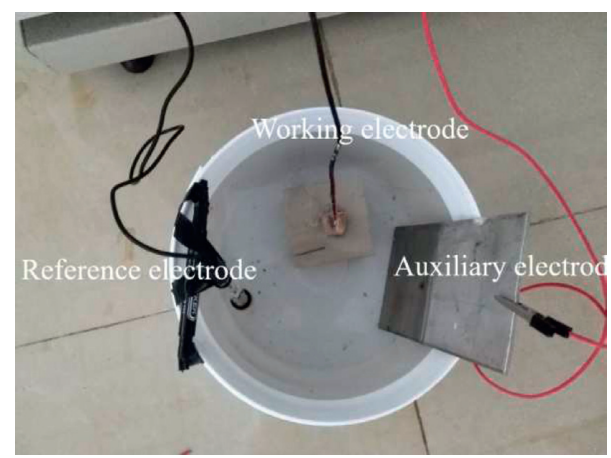

Figure 7: The three-electrode testing method.

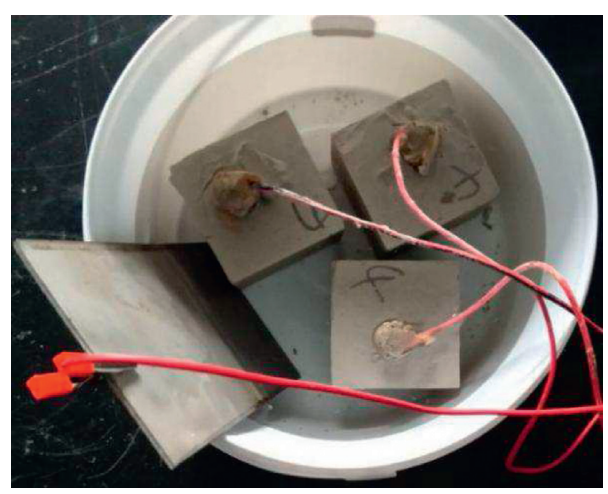

Figure 8: Accelerating the corrosion of the steel bars.

removed (see Figure 9). The part of the steel bar bonding with the cement soil was first cut, and it was then washed, dried, and weighed.

(6) The electrochemical testing equipment could determine the self-corrosion potential of the steel bars, and the actual corrosion rate of the steel bars could be measured by weighing them before and after the corrosion.

\subsection{Mercury Intrusion Test}

2.2.1. Test Introduction. The permeability of cement soil in the corrosive seawater environment is closely related to the compactness of its structure, which correlates strongly with the characteristics of its internal pore structure [26]. During the hardening of cement soil, hydration products fill the original pore spaces, so the porosity and pore size distribution of cement soil change as the hydration of the cementitious material progresses. The mercury intrusion porosimetry (MIP) is a traditional pore measurement method for evaluating the pore structure with over 90 years of history. According to the capillary phenomenon, mercury does not infiltrate cement soil, so external pressure must be applied to diffuse the mercury into the pores of cement soil. According to the classical Lucas-Washburn (LW) equation [27], the pressure for the injection of mercury into cement soil is related to the surface tension, the contact angle, and the diameter of the cement pores as follows:

$$
p=-\frac{4 \sigma \cos \theta}{d}
$$

where $p$ is the mercury injection pressure; $s$ represents the surface tension of mercury and is about $0.473 \mathrm{~N} / \mathrm{m} ; \theta$ indicates the infiltration angle or the contact angle and is about $117^{\circ}-140^{\circ}$ [28]; and $d$ denotes the diameter of the cement pores.

2.2.2. Testing Procedure. PoreMaster 60 GT mercury porosimeter (Figure 10) was utilized to conduct the mercury intrusion test. The sample preparation and the testing method were as follows ():

(1) The cement soil samples containing ferronickel slag powder were cured in the corrosive seawater and purified water environments for the design curing period. It should be noted that, due to the low hydration rate of cement in the cement soil, it must be cured for 90 days before its strength and other properties can be used as an index to evaluate its performance [25]. Thus, this test used the curing periods of 90 days in line with the testing conditions of real projects. However, in this mercury intrusion test, we also found that the pore development law of 60 days is almost the same as 90 days, so the curing periods of 60 days were finally also taken for analysis in the mercury intrusion test. 


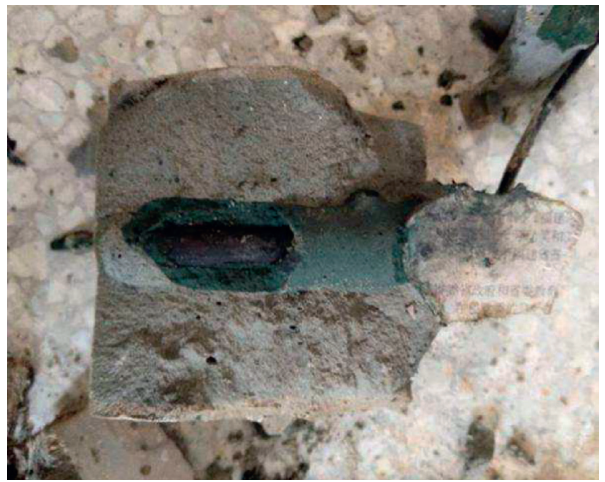

FIGURE 9: Removing the steel bar after breaking the cement soil sample.

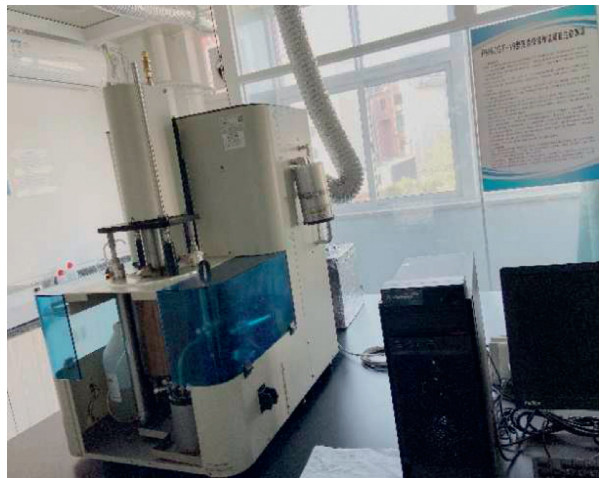

Figure 10: PoreMaster 60 GT mercury porosimeter.

(2) The cement soil sample was broken and trimmed, and the sample for the mercury intrusion test was selected from the area within the range of $2-3 \mathrm{~cm}$ from the surface of the cement soil sample, as shown in Figure 11.

(3) The sample was immediately put into a glass bottle containing absolute ethanol to terminate hydration and dehydration of the cement; it was soaked in ethanol for over 2 days.

(4) The sample was placed in a vacuum drying oven set at a temperature of $50^{\circ} \mathrm{C}$ and dried under vacuum for 2 days.

(5) The dried sample was taken out of the oven and tested immediately.

\section{Results and Discussion}

\subsection{Electrochemical Test}

3.1.1. Self-Corrosion Potential of Steel Bars. PARSTAT 4000 electrochemical comprehensive tester can measure the selfcorrosion potential, the linear polarization resistance, and the corrosion current; however, the linear polarization resistance and the corrosion current measured by this instrument are the overall values of the cement soil and the steel bars. Therefore, these two results are not discussed in this paper. The self-corrosion potential is only that of the steel bar itself, so the self-corrosion potential of the steel bar was selected to evaluate the ability of the cement soil to resist the invasion of the corrosive media. Table 6 presents the evaluation criteria for steel corrosion according to the regulations described in ref. [29].

Figure 12 delineates the self-corrosion potential of the steel bars of the cement soil samples cured in the purified water and the corrosive seawater environment.

Figure 12 demonstrates that, in the purified water environment, the self-corrosion potential of the steel bars embedded in the cement soil containing ferronickel slag powder remains unchanged as the ferronickel slag powder content of the cement soil varies. Regardless of the curing period of the cement soil, the self-corrosion potential of the steel bars is maintained at about $-450 \mathrm{mV}$. Therefore, the electricity parameters set in this experiment can cause the steel bars embedded in the cement soil to corrode. Although the self-corrosion potential of the steel bars remains stable in the purified water environment, the curve shows a slow growth to a certain extent as the ferronickel slag powder content increases. At a curing period of 28 days, the selfcorrosion potential of the steel bars embedded in the cement soil mixed with $40 \%$ ferronickel slag powder increases from -464.66 to $-440.72 \mathrm{mV}$ compared to the reference cement soil with $0 \%$ ferronickel slag powder. At a curing period of 90 days, the self-corrosion potential of the steel bars embedded in the cement soil mixed with $40 \%$ ferronickel slag powder rises from -470.52 to $-444.11 \mathrm{mV}$ compared with the reference cement soil. Therefore, the addition of ferronickel slag powder can raise the self-corrosion potential of 


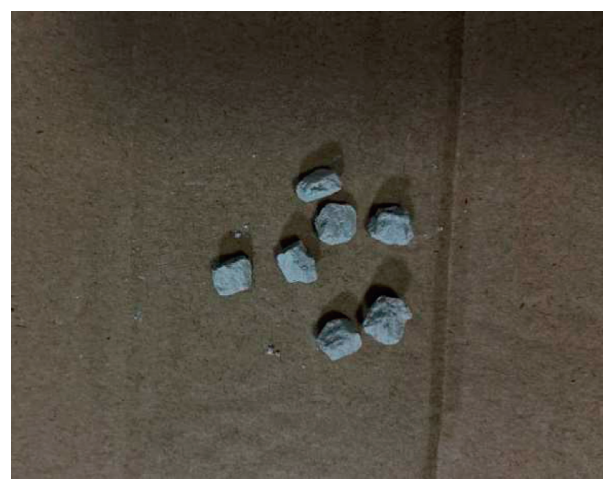

Figure 11: The samples prepared for the mercury intrusion test.

TABLE 6: The evaluation criteria for the corrosion status of steel bars.

\begin{tabular}{lcc}
\hline No. & Potential status of steel bars $(\mathrm{mV})$ & Judgment of steel corrosion status \\
\hline 1 & $<-350$ & There is a $95 \%$ probability that the steel bar is corroded or highly corroded. \\
2 & -200 to -350 & There is a $50 \%$ probability that the steel bar is corroded, and there may be pitting. \\
3 & 0 to -200 & The probability of rusting is $5 \%$; there is no rust, or the rust status is uncertain. \\
\hline
\end{tabular}

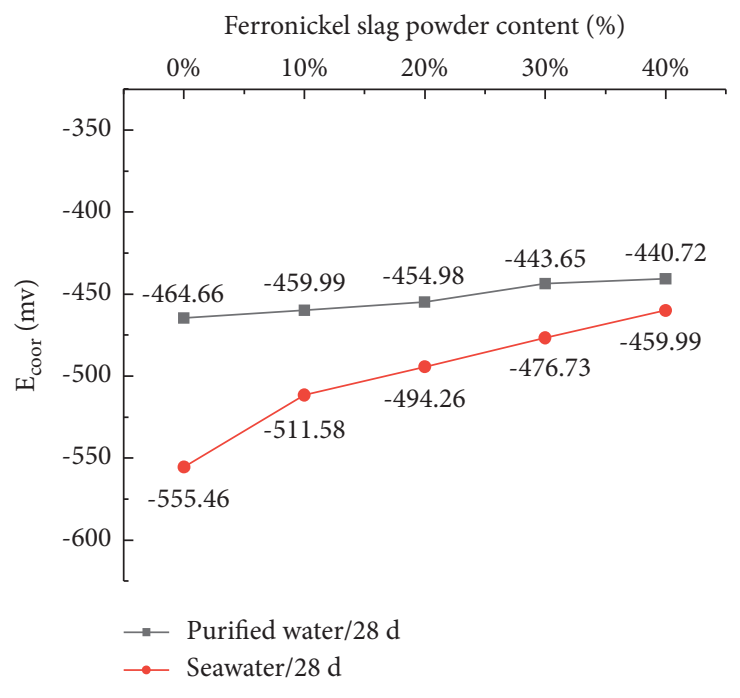

(a)

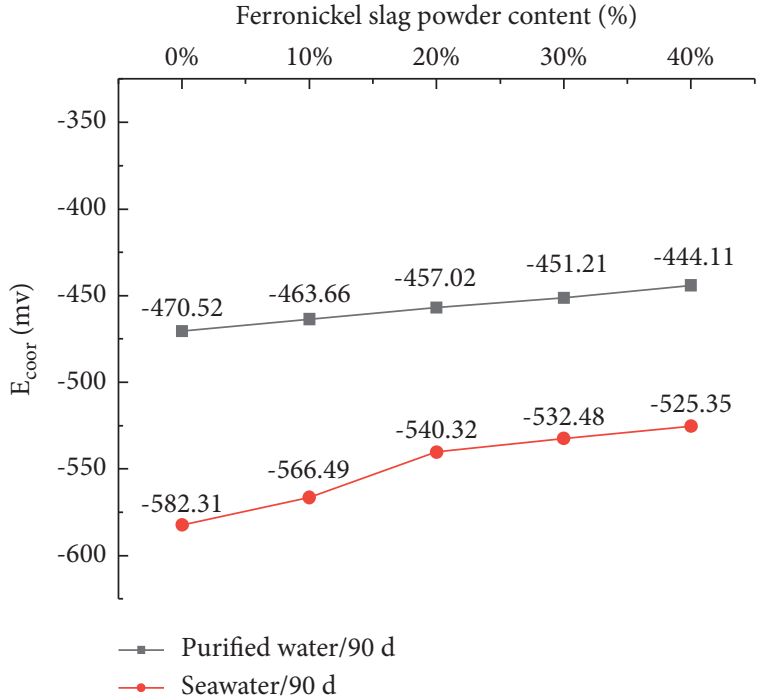

(b)

Figure 12: The comparison of the self-corrosion potential of the steel bars at a curing period of (a) 28 days and (b) 90 days.

the steel bars embedded in the cement soil and thus can reduce the possibility of steel corrosion.

In the corrosive seawater environment, the self-corrosion potential of the steel bars significantly rises with an increase in the ferronickel slag powder content of the cement soil at various curing periods. The rate of increase is also much more significant than that in the purified water environment; the self-corrosion potential of the steel bars is lower than $-450 \mathrm{mV}$. Moreover, at a curing period of 28 days, the self-corrosion potential of the steel bars embedded in the cement soil with $40 \%$ ferronickel slag powder increases from -555.46 to $-459.99 \mathrm{mV}$ compared with the reference cement soil. At a curing period of 90 days, it enlarges from -582.31 to $-525.35 \mathrm{mV}$. Hence, the corrosion degree of the steel bars is more significant in the corrosive seawater environment than in the purified water environment, which indicates that the corrosive seawater environment does have a negative impact on the performance of cement soil. The performance of cement soil in the corrosive seawater environment is determined by the combined effect of the cement soil hardening and the corrosion by the seawater. With the increase in the corrosion time, the superficial and internal deteriorations of the cement soil gradually increase, further giving rise to the undesirable phenomena of cement such as peeling, softening, and passivation of soil which all accelerate the corrosion by the seawater. The addition of ferronickel slag powder significantly raises the self-corrosion potential of the steel bars 
embedded in the cement soil, which implies that the incorporation of ferronickel slag has a very positive effect on the ability of the cement soil to resist seawater invasion.

3.1.2. Corrosion Rate of Steel Bars. According to Faraday's law, the mass of the chemically changed substance at the electrode interface is directly proportional to electricity. The steel mass loss $(\Delta m)$ can be obtained from the magnitude of the current passing through the steel bars and the duration of the power, and then the theoretical corrosion rate of the steel bars can be calculated by

$$
\begin{aligned}
\Delta m & =\frac{M I t}{Z F}, \\
\eta & =\frac{\Delta m}{m}=\frac{M I t}{m Z F},
\end{aligned}
$$

where $\Delta m$ is the mass loss of the steel bar after electrification and corrosion; $M$ indicates the molar mass of iron and is $56 \mathrm{~g} / \mathrm{mol}$; $I$ is the electric current; $t$ stands for the energization time; $Z$ is the chemical valence of iron ions, and its average value equals $2.5 ; F$ denotes the Faraday's constant and equals $96,500 \mathrm{C} / \mathrm{mol} ; \eta$ represents the corrosion rate of the steel bar; and $m$ is the initial mass of the steel bar.

The cement soil sample was broken, and the part bonded to the steel bar was removed. The actual corrosion rate of the steel bars after being corroded by electricity was measured by the weighing method as expressed in Equation (8):

$$
\eta^{\prime}=\frac{\Delta m^{\prime}}{m}=1-\frac{m^{\prime} l}{m l^{\prime}}
$$

where $\eta^{\prime}$ represents the actual corrosion rate of the steel bar; $\Delta m$ ' indicates the mass loss of the steel bar after corrosion; $m$ is the initial mass of the steel bar; $m$ ' denotes the mass of the steel bar after corrosion; $l$ is the length of the cut section of the steel bar; and $l$ stands for the initial length of the steel bar.

According to the weighing method, Figure 13 delineates the actual corrosion rate of the steel bars embedded in the cement soil.

Figure 13 demonstrates that the higher the actual corrosion rate of the steel bars is, the higher the permeability of the cement soil becomes and the lower the impermeability is.

The corrosion rate of the steel bars increases gradually with raising the curing period in the same environment and at a similar content of ferronickel slag powder, indicating that the impermeability of the cement soil declines gradually with the curing period.

Regarding the influence of the ferronickel slag powder content on the impermeability of the cement soil, after 28 days of curing, the corrosion rate of the steel bars embedded in the cement soil samples with a $10 \%, 20 \%, 30 \%$, and $40 \%$ mass replacement ratio of ferronickel slag powder and mineral powder composite decreases by $5.76 \%, 19.7 \%$, $29.09 \%$, and $34.85 \%$ in the purified water environment and by $19.51 \%, 21.8 \%, 38.2 \%$, and $51.97 \%$, respectively, in the seawater environment compared with the reference sample with a mass replacement ratio of the ferronickel slag powder and mineral powder composite of $0 \%$.
After 90 days of curing, at a mass replacement ratio of ferronickel slag powder and mineral powder composite of $10 \%, 20 \%, 30 \%$, and $40 \%$, the corrosion rate of the steel bars decreases by $11.26 \%, 21.7 \%, 29.95 \%$, and $36.81 \%$ in the purified water environment and by $26.46 \%, 31.9 \%, 46.08 \%$, and $59.49 \%$, respectively, in the seawater environment. The results indicate that regardless of the curing period and the corrosive environment, when the replacement ratio of the ferronickel slag powder is within $0 \%-40 \%$, the actual corrosion rate of the steel bars decreases with increasing the ferronickel slag powder content in cement soil and the impermeability of the cement soil improves.

Regarding the influence of the curing conditions on the impermeability of the cement soil, the corrosion rate of the steel bars embedded in the cement soils containing $0 \%, 10 \%$, $20 \%, 30 \%$, and $40 \%$ ferronickel slag powder is, respectively, $0.85,0.58,0.80,0.61$, and 0.36 times more significant in the corrosive seawater environment than in the purified water environment at a curing period of 28 days and 1.17, 0.80, $0.89,0.67$, and 0.39 times at a curing period of 90 days. The smaller the multiplication factor is, the better the impermeable effect exerted by the ferronickel slag powder is in the seawater environment than in the purified water environment. Thus, regardless of the curing period, the actual corrosion rate is always more remarkable in the seawater environment than the purified water environment, indicating that the corrosive environment of seawater has an adverse effect on accelerating the corrosion of the steel bars in the cement soil. In addition, the multiplication factor is the largest when the ferronickel slag powder content is $0 \%$, while it is the smallest when the ferronickel slag powder content is $40 \%$, implying that the impermeable effect is the best when the ferronickel slag powder content is $40 \%$.

\subsection{Mercury Intrusion Test}

3.2.1. Mercury Intrusion Test Results. The pore structure and pore size distribution of the cement soil containing ferronickel slag powder in the purified water environment and the corrosive seawater environment are presented in Tables 7 and 8 for a curing period of 60 and 90 days, respectively. It should be noted that the total porosity herein reflects the total pore volume of cement soil, and its magnitude directly affects the impermeability of cement soil. The most probable pore size is the one with the highest probability of occurrence in the cement soil. In fact, if the pore size of cement soil is smaller than this value, the internal pores cannot connect [30]. Therefore, the most probable pore size is one of the critical factors affecting the impermeability of cement soil. In addition, $\mathrm{Wu}$ [31] believed that not all pores in the concrete structure were harmful to its performance and classified different pores according to their diameter, as defined in Tables 7 and 8. Chen et al. [32] also reached a similar conclusion that the microcapillary pores with a diameter in the range of $10-100 \mathrm{~nm}$ had the most significant impact on the impermeability of cementbased materials. Tables 7 and 8 list the proportions of harmless pores, less harmful pores, harmful pores, and more harmful pores at a curing period of 60 and 90 days, respectively, 


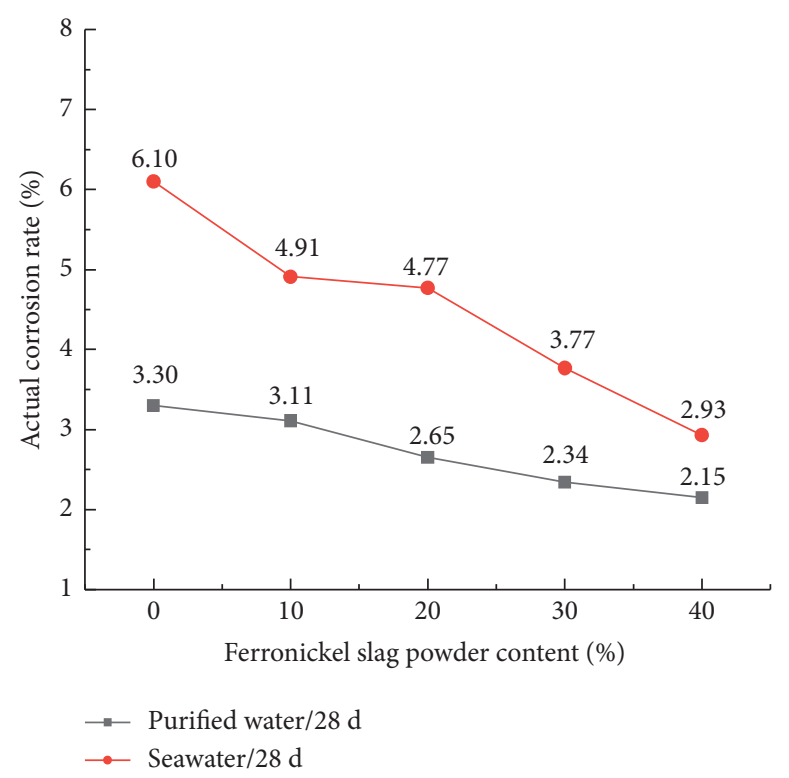

(a)

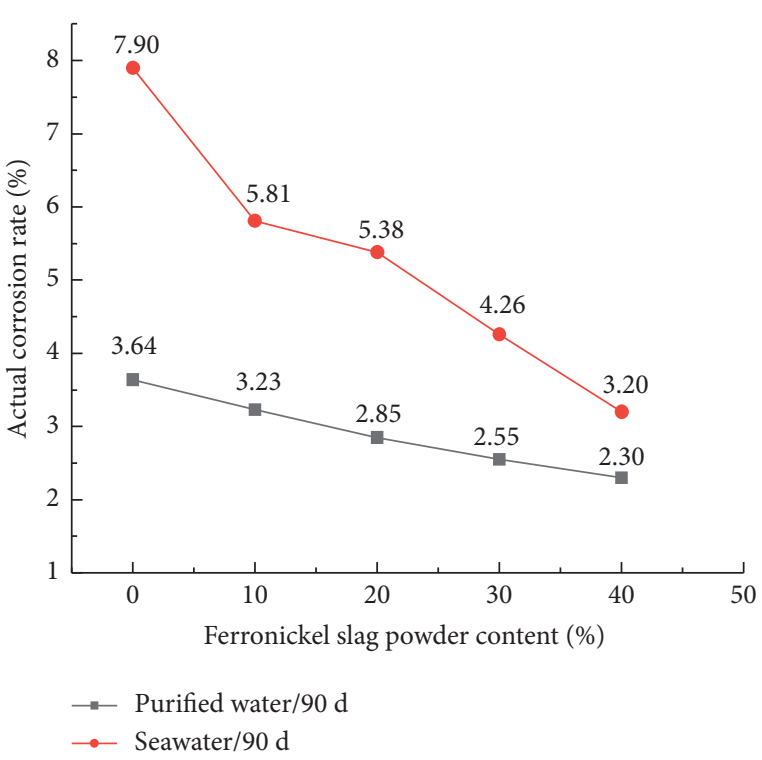

(b)

Figure 13: The actual corrosion rate of the steel bars embedded in the cement soil cured for (a) 28 days and (b) 90 days.

TABLE 7: The pore characteristics of the cement soil containing ferronickel slag powder at a curing period of 60 days.

\begin{tabular}{|c|c|c|c|c|c|c|c|}
\hline $\begin{array}{l}\text { Sample } \\
\text { ID }\end{array}$ & $\begin{array}{l}\text { Curing } \\
\text { condition }\end{array}$ & $\begin{array}{l}\text { Total } \\
\text { porosity } \\
(\%)\end{array}$ & $\begin{array}{l}\text { Most } \\
\text { probable } \\
\text { pore size } \\
(\mathrm{nm})\end{array}$ & $\begin{array}{l}\text { Harmless pore } \\
(d \leq 20 \mathrm{~nm}) \\
(\%)\end{array}$ & $\begin{array}{c}\text { Less harmful pore } \\
(20 \mathrm{~nm}<d \leq 50 \mathrm{~nm})(\%)\end{array}$ & $\begin{array}{c}\text { Harmful pore } \\
(50 \mathrm{~nm}<d \leq 200 \mathrm{~nm}) \\
(\%)\end{array}$ & $\begin{array}{c}\text { More harmful } \\
\text { pore } \\
(d \geq 200 \mathrm{~nm})(\%)\end{array}$ \\
\hline A- 0 & $\begin{array}{l}\text { Purified } \\
\text { water }\end{array}$ & 37.00 & 64.75 & 19.98 & 25.34 & 33.15 & 21.53 \\
\hline A-1 & $\begin{array}{l}\text { Purified } \\
\text { water }\end{array}$ & 35.6 & 54.14 & 21.49 & 28.21 & 28.62 & 21.68 \\
\hline A-2 & $\begin{array}{c}\text { Purified } \\
\text { water }\end{array}$ & 34.47 & 48.91 & 22.02 & 30.16 & 27.54 & 20.28 \\
\hline A-3 & $\begin{array}{c}\text { Purified } \\
\text { water }\end{array}$ & 34.06 & 45.37 & 22.85 & 29.81 & 29.67 & 17.67 \\
\hline A- 4 & $\begin{array}{c}\text { Purified } \\
\text { water }\end{array}$ & 32.59 & 42.28 & 23.28 & 34.03 & 33.58 & 9.11 \\
\hline B- 0 & Seawater & 50.47 & 67.85 & 17.04 & 24.86 & 32.07 & 26.03 \\
\hline B-1 & Seawater & 49.58 & 60.03 & 17.54 & 28.96 & 32.69 & 20.81 \\
\hline B-2 & Seawater & 47.03 & 50.88 & 17.93 & 29.07 & 33.45 & 19.55 \\
\hline B-3 & Seawater & 39.80 & 48.36 & 18.31 & 30.06 & 32.29 & 19.34 \\
\hline B- 4 & Seawater & 34.63 & 44.96 & 19.11 & 31.13 & 33.55 & 16.21 \\
\hline
\end{tabular}

according to Wu's classification method, and the sum of the proportion of the four pore types is $100 \%$.

3.2.2. Discussion of the Mercury Intrusion Test Results. The mercury intrusion test results can be analyzed by combining Tables 7 and 8, presenting the pore characteristics of the different cement soil samples containing ferronickel slag powder.

(1) Most Probable Pore Size: Table 7 demonstrates that, at a curing period of 60 days, cement soil samples A-0, A-1, A-2, A-3, and A-4 containing ferronickel slag powder have the most probable pore size of $64.75,54.14,48.91,45.37$, and
$42.28 \mathrm{~nm}$, respectively, in the purified water environment. This finding implies that with an increase in the ferronickel slag powder content, the most probable pore size of the cement soil decreases significantly. In other words, the addition of ferronickel slag powder to the cement soil improves its compactness and structural integrity, thereby enhancing its impermeability. In the corrosive seawater environment, the most probable pore size of cement soil samples B-0, B-1, B-2, B-3, and B-4 is 67.85, 60.03, 50.88, 48.36 , and $44.96 \mathrm{~nm}$, respectively. Compared with the purified water environment, the value of the most probable pore size of the cement enlarges in the corrosive seawater environment, indicating that the cement soil already 
TABLE 8: The pore characteristics of the cement soil containing ferronickel slag powder at a curing period of 90 days.

\begin{tabular}{|c|c|c|c|c|c|c|c|}
\hline $\begin{array}{l}\text { Sample } \\
\text { ID }\end{array}$ & $\begin{array}{l}\text { Curing } \\
\text { condition }\end{array}$ & $\begin{array}{l}\text { Total } \\
\text { porosity } \\
(\%)\end{array}$ & $\begin{array}{l}\text { Most } \\
\text { probable } \\
\text { pore size } \\
(\mathrm{nm})\end{array}$ & $\begin{array}{l}\text { Harmless pore } \\
(d \leq 20 \mathrm{~nm}) \\
(\%)\end{array}$ & $\begin{array}{c}\text { Less harmful pore } \\
(20 \mathrm{~nm}<d \leq 50 \mathrm{~nm})(\%)\end{array}$ & $\begin{array}{c}\text { Harmful pore } \\
(50 \mathrm{~nm}<d \leq 200 \mathrm{~nm}) \\
(\%)\end{array}$ & $\begin{array}{c}\text { More harmful } \\
\text { pore } \\
(d \geq 200 \mathrm{~nm})(\%)\end{array}$ \\
\hline A- 0 & $\begin{array}{c}\text { Purified } \\
\text { water }\end{array}$ & 36.47 & 60.73 & 20.02 & 27.28 & 37.15 & 15.55 \\
\hline A-1 & $\begin{array}{c}\text { Purified } \\
\text { water }\end{array}$ & 34.28 & 51.41 & 22.18 & 28.13 & 34.12 & 15.57 \\
\hline A-2 & $\begin{array}{c}\text { Purified } \\
\text { water }\end{array}$ & 33.68 & 47.44 & 22.52 & 30.94 & 31.34 & 15.2 \\
\hline A-3 & $\begin{array}{c}\text { Purified } \\
\text { water }\end{array}$ & 32.22 & 42.71 & 23.31 & 31.47 & 30.39 & 14.83 \\
\hline A- 4 & $\begin{array}{l}\text { Purified } \\
\text { water }\end{array}$ & 31.19 & 39.79 & 24.92 & 33.45 & 28.96 & 12.67 \\
\hline B-0 & Seawater & 52.89 & 68.42 & 18.67 & 24.98 & 33.77 & 22.58 \\
\hline B-1 & Seawater & 52.43 & 66.72 & 19.77 & 27.11 & 33.83 & 19.29 \\
\hline B-2 & Seawater & 41.23 & 61.52 & 20.19 & 27.36 & 33.43 & 19.02 \\
\hline B-3 & Seawater & 36.52 & 51.76 & 20.99 & 33.3 & 29.4 & 16.31 \\
\hline B-4 & Seawater & 34.81 & 49.73 & 21.73 & 32.74 & 34.54 & 10.99 \\
\hline
\end{tabular}

deteriorates in the corrosive seawater environment. This finding implies that adding the ferronickel slag powder to the cement can alleviate the corrosion by the seawater and improve the impermeability of the cement soil. At a curing period of 90 days, the hardening effect of the cement soil is stable, and the changing rule of the most probable pore size of the cement soil containing the ferronickel slag powder is similar to that of the samples cured for 60 days. However, the reduction in the most probable pore size of the cement is higher at a curing period of 90 days than 60 days. In other words, with an increase in the curing period, the internal microstructure of the cement soil is densified, and the mitigation effect of the ferronickel slag powder increases.

(2) Total Porosity: At a curing period of 60 days, the total porosity of the cement soil with $0 \%, 10 \%, 20 \%, 30 \%$, and $40 \%$ ferronickel slag powder is $37.00 \%, 35.60 \%, 34.47 \%, 34.06 \%$, and $32.59 \%$, respectively, in the purified water environment and $50.47 \%, 49.58 \%, 47.03 \%, 39.80 \%$, and $34.63 \%$, respectively, in the corrosive seawater environment. It can be inferred from the characteristic parameter of the total porosity of the cement soil that the ferronickel slag powder can reduce the porosity of the cement soil and improve its internal microstructure; this feature is more evident under the corrosion effect of seawater. At a curing period of 90 days, the hydration of the cement tends to be complete, and the total porosity of the cement soil at various mix ratios shows a downward trend compared with that of the cement samples cured for 60 days. Moreover, the total porosity of the cement soil decreases with the addition of the ferronickel slag powder, and the corrosion by the marine environment causes the cement porosity to rise.

(3) Pore Size Distribution: With an increase in the ferronickel slag powder content of cement soil, the proportion of its harmless pores with a pore size of smaller than $20 \mathrm{~nm}$ enlarges slightly, while that of its less harmful pores with a pore size in the range of $20-50 \mathrm{~nm}$ rises. At a curing period of 60 days, the sum of the proportions of the harmless pores and less harmful pores of cement soil samples containing ferronickel slag A-0, A-1, A-2, A-3, and A-4 in the purified water environment is $45.32 \%, 49.70 \%, 52.18 \%, 52.66 \%$, and $57.31 \%$, respectively, and that of cement soil samples containing ferronickel slag B-0, B-1, B-2, B-3, and B-4 in the corrosive seawater environment is $41.90 \%, 46.50 \%, 47.00 \%$, $48.37 \%$, and $50.24 \%$, respectively.

As the ferronickel slag powder content increases, the proportions of the harmless pores and the less harmful pores rise but that of the harmful pores and the more harmful pores declines. This result indicates that the active substances of the cement soil, namely, the cement and the ferronickel slag powder, continue to function, and the reaction products continue to increase. Thus, the harmless pores inside the cement structure continue to rise in the purified water environment. Moreover, the corrosion effect of the corrosive seawater environment on the cement soil continues, so the harmful pores of the cement soil increase significantly in the corrosive seawater environment. In the purified water and corrosive seawater environments, the variations in the sum of the proportions of the harmless pores and less harmful pores of the cement soils cured for 90 days are basically similar to those of the cement soil samples cured for 60 days. However, the range of the change in the proportions of all types of the pores is more apparent at a curing period of 90 days than 60 days; especially, the proportions of the harmful pores and the more harmful pores in the corrosive seawater environment increase significantly.

There are many corrosive ions such as $\mathrm{Cl}^{-}, \mathrm{SO}_{4}^{2-}$, and $\mathrm{Mg}^{2+}$ in the corrosive seawater environment that can react with the internal $\mathrm{Ca}(\mathrm{OH})_{2}$ of the cement soil containing ferronickel slag powder to form a large volume of gypsum $\left(\mathrm{CaSO}_{4} \cdot 2 \mathrm{H}_{2} \mathrm{O}\right)$. The gypsum can further react with the hydration product of the cement, that is, calcium aluminate hydrate, to form alumina, ferric oxide, and trisulfate (Aft, ettringite) [33]. When a certain amount of $\mathrm{SO}_{4}^{2-}$ in the soil reacts to a certain degree, it causes the cement soil to expand, loosen, and even damage. However, $\mathrm{Cl}^{-}$and $\mathrm{Mg}^{2+}$ can react 
with $\mathrm{Ca}^{2+}$ in the cement soil to result in $\mathrm{CaCl}_{2}$ with high solubility and $\mathrm{Mg}(\mathrm{OH})_{2}$ with low strength, making $\mathrm{Ca}^{2+}$ in the cement soil continue to precipitate and form pores [34]. Therefore, the porosity, the most probable pore size, and the number of harmful pores and more harmful pores of the ferronickel slag cement soil increase in the corrosive seawater environment.

\section{Conclusions}

This paper used the electrochemical testing method to accelerate the corrosion of steel bars embedded in cement soil. It comprehensively evaluated the impermeability of cement soil by considering the independent variables, namely, the ferronickel slag powder content, the curing period, and the curing environment. The dependent parameters were the self-corrosion potential of the steel bars and their actual corrosion rate. Subsequently, the mercury intrusion test was employed to analyze the change in the pore characteristics of the cement soil and examine the influence of the change in the pore characteristics on the impermeability of the cement soil. From the above results and discussion, the following conclusions can be drawn:

(i) The self-corrosion potential of the steel bars after their corrosion was accelerated using the electrochemical method. The self-corrosion potential of the steel bars correlates positively with the impermeability of the cement soil. Moreover, the selfcorrosion potential of the cement soil at each curing period in the purified water environment shows a slow growth with the increase in the ferronickel slag powder content, but its improvement effect is limited. However, the corrosive seawater environment has an adverse effect on the corrosion of the steel bars embedded in the cement soil. With an increase in the ferronickel slag powder content, the self-corrosion potential of the steel bars gradually rises, which leads to the increase in the impermeability of cement soil and the enhanced improvement effect.

(ii) It is found that the actual corrosion rate of the steel bars correlates negatively with the impermeability of the cement soil. At a low ferronickel slag content of the cement soil, the actual corrosion rate of the steel bars embedded in the cement soil is significant, and its ability to resist external corrosion is weak. As the ferronickel slag powder content increases, the actual corrosion rate of the steel bars gradually declines, and the cement soil increasingly resists the invasion of corrosive substances.

(iii) The impermeability of the cement soil was evaluated by two methods: the self-corrosion potential of the steel bars and their actual corrosion rate. Both methods confirm that incorporating ferronickel slag powder into cement soil can improve its impermeability in the corrosive seawater environment. As the ferronickel slag powder content increases, the impermeability of the cement soil is gradually enhanced, and the optimum ferronickel slag powder content is $40 \%$.

(iv) It can be inferred from the results of the mercury intrusion test that the most probable pore size, the harmful and more harmful pores, and the total porosity of the cement soil gradually decline with an increase in the ferronickel slag powder content, so the compactness of the cement soil enlarges. Therefore, adding the ferronickel slag powder is beneficial to developing the strength and impermeability of cement soil.

(v) Compared with the traditional penetration test, the electrochemical test enjoys the advantage of rapid, nondestructive, and repeatable measurements, saving time and improving the test efficiency. Employing the electrochemical tests to evaluate the impermeability of the cement soil is an innovative method, and it is worth being popularized in engineering practices.

\section{Data Availability}

All the data included in this study are available upon request by contact with the corresponding author.

\section{Conflicts of Interest}

The authors declare that there are no conflicts of interest regarding the publication of this paper.

\section{Acknowledgments}

This research was funded by the (Natural Science Foundation of Fujian Province (Grant no. 2019J01883), Science and Technology Project Foundation of the (Education Department Of Fujian Province (Grant no. JAT170611), and (National Natural Science Foundation of China Strait Joint Fund Project (Grant no. U1605242).

\section{References}

[1] A. D. Werner, M. Bakker, V. E. A. Post et al., "Seawater intrusion processes, investigation and management: recent advances and future challenges - ScienceDirect," Advances in Water Resources, vol. 51, no. 2, pp. 3-26, 2013.

[2] M. A. Mohammed Al-Bared and A. Marto, "A review on the geotechnical and engineering characteristics of marine clay and the modern methods of improvements," Malaysian Journal of Fundamental and Applied Sciences, vol. 13, no. 4, pp. 825-831, 2017.

[3] F. Xiong, H. Xing, and H. Li, "Experimental study on the effects of multiple corrosive ion coexistence on soil-cement characteristics," Soils and Foundations, vol. 59, no. 2, pp. 398-406, 2019.

[4] X. Li, Y. Yang, H. Zhang, and Y. Yi, "Mechanical properties and failure mechanism of cemented red clay under chemical erosion environment," International Journal of Environment and Pollution, vol. 59, no. 2-4, pp. 156-168, 2016.

[5] M. A. Tahir, "Comparative sulphate resistance of pozzolanic cement mortars," Urban and Civil Engineering, vol. 10, no. 6, pp. 729-732, 2017. 
[6] A. Allahverdi, M. Akhondi, and M. Mahinroosta, "A composite cement of high magnesium sulphate resistance," Materiales de Construcción, vol. 68, no. 330, p. 154, 2018.

[7] W. Wongprachum, M. Sappakittipakorn, P. Sukontasukkul, P. Chindaprasirt, and N. Banthia, "Resistance to sulfate attack and underwater abrasion of fiber reinforced cement mortar," Construction and Building Materials, vol. 189, pp. 686-694, 2018.

[8] J. X. Yang, "Experimental study on permeability of basalt fiber cement soil," Science Technology and Engineering, vol. 20, no. 8, pp. 3217-3221, 2020.

[9] F. Chen, S. H. Tong, and J. H. Ren, "Impermeability of basalt fiber soil-cement," Journal of Shenzhen University (Science and Technology Edition), vol. 38, no. 2, pp. 157-162, 2021.

[10] Z. D. Wang, S. T. Zhou, and W. Fang, "Experimental study on mechanical properties of cement soil modified by bentonite," Bulletin of the Chinese Ceramic Society, vol. 38, no. 10, pp. 3287-3292, 2019.

[11] L. Wang, X. Li, Y. Cheng, Y. Zhang, and X. Bai, "Effects of coal-bearing metakaolin on the compressive strength and permeability of cemented silty soil and mechanisms," Construction and Building Materials, vol. 186, pp. 174-181, 2018.

[12] H. Zeng, Y. Lai, S. Qu, and F. Yu, "Effect of graphene oxide on permeability of cement materials: an experimental and theoretical perspective," Journal Of Building Engineering, vol. 41, no. 4, Article ID 102326, 2021

[13] Y. K. Shi, F. Liu, S. L. Chen et al., "Research on the mechanical properties of fiber cement soil under acid-alkali environment," Bulletin of the Chinese Ceramic Society, vol. 39, no. 10, pp. 3298-3303+3320, 2020.

[14] S. Chaiyasat, "“Permeability of soil cement admixed with air foam," IOP Conference Series," Materials Science and Engineering, vol. 652, pp. 12-22, 2019.

[15] G. Zhang, N. Wang, M. Chen, and Y. Wang, "Viscosity and structure of $\mathrm{CaO}-\mathrm{SiO}_{2}-$ " $\mathrm{FeO}$ " $-\mathrm{Al}_{2} \mathrm{O}_{3}-\mathrm{MgO}$ system during iron-extracting process from nickel slag by aluminum dross. Part 1: coupling effect of "FeO" and $\mathrm{Al}_{2} \mathrm{O}_{3}$," Steel Research International, vol. 89, no. 10, pp. 1-8, 2018.

[16] W. J. Cho, M. J. Kim, and D. S. V. Lee, "Characterization of Portland cement incorporated with FNS," Advances in Materials Science and Engineering, vol. 2020, pp. 1-9, 2020.

[17] A. K. Saha and P. K. Sarker, "Acid resistance of mortar using ferronickel slag (FNS) aggregate and ground FNS as supplementary cementitious material," ACI Materials Journal, vol. 116, no. 6, pp. 65-76, 2019.

[18] H. Tang, Z. Peng, F. Gu et al., "Utilization of ferronickel slag for producing concrete," Ceramics International, vol. 47, no. 7, pp. 10019-10026, 2021.

[19] A. K. Saha and P. K. Sarker, "Effect of sulphate exposure on mortar consisting of ferronickel slag aggregate and supplementary cementitious materials - ScienceDirect," Journal of Building Engineering, vol. 28, Article ID 101012, 2019.

[20] F. Chen and S. Tong, "Experimental study on the strength of soil-cement with additions of mineral powder and ferronickel slag powder," International Journal of Mining and Mineral Engineering, vol. 11, no. 3, p. 218, 2020.

[21] C. H. Zhu and Z. H. Wang, "Experimental research on the variation regularity of permeability coefficient of cement soil," Journal Of Yangtze River Scientific Research Institute, vol. 30, no. 4, pp. 59-63, 2013.

[22] Z. Li, Z. Q. Jin, S. S. Shao et al., "A review on reinforcement corrosion mechanics and monitoring techniques in concrete in marine environment," Materials Review, vol. 32, no. 23, pp. 4170-4181, 2018.
[23] X. Shi, N. Xie, K. Fortune, and J. Gong, "Durability of steel reinforced concrete in chloride environments: an overview," Construction and Building Materials, vol. 30, pp. 125-138, 2012.

[24] F. Chen and S. H. Tong, "Experimental study on the impermeability of ferronickel slag powder soil-cement in marine environments," Solid State Technology, vol. 64, pp. 1238-1247, 2021.

[25] China Architecture \& Building Press: Beijing, Technical Code for Ground Treatment of Buildings (JGJ 79)pp. 50-51, Industry Standard of the People's Republic of China, Beijing, China, 1st ed. edition, 2012.

[26] Y. Gao, K. Wu, and Q. Yuan, "Limited fractal behavior in cement paste upon mercury intrusion porosimetry test: analysis and models," Construction and Building Materials, vol. 276, no. 1, Article ID 122231, 2021.

[27] E. W. Washburn, "Note on a method of determining the distribution of pore sizes in a porous material," Proceedings of the National Academy of Sciences, vol. 7, no. 4, pp. 115-116, 1921.

[28] D. H. B. A. Sellevold and, "Mercury porosimetry of hardened cement paste: the influence of particle size," Cement-andConcrete-Research, vol. 5, no. 2, pp. 171-177, 1975.

[29] China Architecture \& Building Press: Beijing, Technical Standard for Inspection of Building structure(GB/T 50344) pp. 142-143, Ministry of Construction of the People's Republic of China, Beijing, China, 2nd ed. edition, 2019.

[30] J. Zhang, H. E. Chen, Z. F. Chen et al., "Research on variation of porosity in destruction process of cement stabilized soil," Global Geology, vol. 15, no. 3, pp. 216-220, 2012.

[31] Z. W. Wu, "Discussion on the recent development direction of concrete science and technology," Journal of the Chinese Ceramic Society, vol. 3, pp. 262-270, 1979.

[32] L. J. Chen, Y. Wang, and X. Yin, "Effect of aperture size on impermeability of concrete," Journal of the Chinese Ceramic Society, vol. 33, no. 4, pp. 500-505, 2005.

[33] A. K. Saha and P. K. Sarker, "Durability of mortar incorporating ferronickel slag aggregate and supplementary cementitious materials subjected to wet-dry cycles," International Journal of Concrete Structures and Materials, vol. 12, no. 1, p. 29, 2018.

[34] P. Sikora, K. Cendrowski, M. Abd Elrahman, S.-Y. Chung, E. Mijowska, and D. Stephan, "The effects of seawater on the hydration, microstructure and strength development of Portland cement pastes incorporating colloidal silica," Applied Nanoscience, vol. 10, no. 8, pp. 2627-2638, 2019. 